Bull. Mater. Sci., Vol. 6, No. 6, December 1984, pp. 1063-1067. (C) Printed in India.

\title{
Infrared absorption in spinel ferrites
}

\author{
T T SRINIVASAN, C M SRIVASTAVA, N VENKATARAMANI* and \\ M J PATNI* \\ Department of Physics, *Materials Science Centre, Indian Institute of Technology, Powai, \\ Bombay 400076 , India
}

MS received 31 May 1983

\begin{abstract}
The IR spectra of a number of ferrites, $\mathrm{MFe}_{2} \mathrm{O}_{4}, \mathrm{M}(\mathrm{Mn}, \mathrm{Fe}, \mathrm{Co}, \mathrm{Ni}, \mathrm{Cu}$ and $\mathrm{Zn})$ have been studied at room temperature in the range $200-1000 \mathrm{~cm}^{-1}$. In all the cases the spectrum consists of four bands, two of which have strong absorption while the other two have weak absorption and of ten appear as shoulders on the main band. However up to $20 \%$ of the inverse ferrite, the shoulder in the low energy side appears as a band. In this paper we have analysed the origin of the above bands.
\end{abstract}

Keywords. IR spectrum; ferrites; centre frequency; force constants.

\section{Introduction}

Infrared spectrum of ferrites has been studied by Waldron (1955). The effect of a JahnTeller ion on the lattice vibrational frequencies of nickel ferrite has also been studied by Srivastava and Srinivasan (1982). Waldron has assumed that the 14 atoms in the primitive unit cell of a spinel lattice can be divided into two $\mathrm{MO}_{4}$ groups and one $\mathrm{Fe}_{4}$ group of tetrahedral symmetry. This allows the classification of the vibrations into the point group $T_{d}$. The conclusions reached by him are not very satisfactory. For example, the force constants $K_{t}$ for the $t-o$ bond for the normal ferrite $\mathrm{ZnFe}_{2} \mathrm{O}_{4}$ and $\mathrm{MnFe}_{2} \mathrm{O}_{4}$ are substantially smaller than that for the inverse spinels like $\mathrm{Co}, \mathrm{Fe}$ and $\mathrm{Ni}$ ferrites. The normal ferrites are formed due to the strong tetrahedral site preference of the divalent ions like $\mathrm{Zn}^{2+}$. As the size of the $\mathrm{Zn}^{2+}(0.74 \AA)$ ion is larger than the $\mathrm{Fe}^{3+}(0.64 \AA)$ ion, the overlap and strength of the $t-o$ bond is expected to be greater for $\mathrm{ZnFe}_{2} \mathrm{O}_{4}$ than say for $\mathrm{Fe}_{3} \mathrm{O}_{4}$. We would therefore expect that the increased covalency in the bond would more than compensate for the decrease in the electrostatic energy due to the change for $3+$ and $2+$ state of the metal ion. Further each of the two broad bands showed asymmetry in the line shape. Waldron (1955) has also reported the presence of low as well as high frequency shoulders in his observations. We have analysed them as additional vibrational modes of the system. The IR frequencies are given in tables 1 and 2.

\section{Experimental}

The samples were prepared using the normal conventional ceramic technique. All the samples had densities higher than $97 \%$ of their $\mathrm{x}$-ray density. The x-ray analysis showed a single phase and a spinel structure. 
Table 1. IR spectral frequencies of ferrites.

\begin{tabular}{lcccc}
\hline $\mathrm{MFe}_{2} \mathrm{O}_{4}$ & \multicolumn{4}{c}{ Centre frequency (linewidth) $\mathrm{cm}^{-1}$} \\
\cline { 2 - 5 } $\mathrm{M}=$ & $T_{2}^{o}$ & $T_{2}^{\mathrm{t}}$ & $E^{\circ}$ & $E^{\prime}$ \\
\hline $\mathrm{Mn}$ & 330 & 400 & 545 & 640 \\
& $(88)$ & $(100)$ & $(78)$ & $(90)$ \\
$\mathrm{Fe}^{*}$ & 350 & 410 & 590 & 640 \\
& $(62)$ & $(55)$ & $(78)$ & $(100)$ \\
$\mathrm{Co}^{*}$ & 340 & 390 & 570 & 650 \\
& $(67)$ & $(50)$ & $(75)$ & $(78)$ \\
$\mathrm{Ni}$ & 340 & 396 & 587 & 660 \\
& $(105)$ & $(40)$ & $(100)$ & $(110)$ \\
$\mathrm{Cu}$ & 330 & 400 & 565 & 620 \\
& $(70)$ & $(90)$ & $(80)$ & $(75)$ \\
$\mathrm{Zn}$ & 338 & 415 & 550 & 660 \\
& $(105)$ & $(120)$ & $(85)$ & $(160)$ \\
& & & &
\end{tabular}

*Waldron's (1955) data.

Table 2. IR spectral frequencies of $\mathrm{Zn}_{1-x} \mathrm{Ni}_{x} \mathrm{Fe}_{2} \mathrm{O}_{4}(0 \leqslant x \leqslant 1)$.

\begin{tabular}{lcccc}
\hline & \multicolumn{4}{c}{ Centre frequency of $\left(\mathrm{cm}^{-1}\right)$} \\
\cline { 2 - 5 } & $T_{2}^{o}$ & $T_{2}^{1}$ & $E^{o}$ & $E^{\mathbf{1}}$ \\
\hline 0 & 338 & 415 & 550 & 660 \\
0.02 & 338 & 415 & 555 & 670 \\
0.04 & 338 & 420 & 553 & 670 \\
0.06 & 340 & 420 & 555 & 670 \\
0.08 & 338 & 421 & 555 & 670 \\
0.15 & 340 & 421 & 559 & 670 \\
$0-2$ & 340 & 422 & 562 & 670 \\
1 & 340 & 396 & 587 & 660 \\
\hline
\end{tabular}

The ferrite powders were dispersed in $\mathrm{KBr}$ and pressed to get a clear disc. The spectra in the range of $200-1000 \mathrm{~cm}^{-1}$ were recorded at room temperature (SP 2000 IR Spectrameter, TYPE UNICHEM make). In order to examine the effect of the transformation from the normal to the inverse ferrite on the lattice modes of vibration we have studied the IR spectra of $\mathrm{Zn}_{1-x} \mathrm{Ni}_{x} \mathrm{Fe}_{2} \mathrm{O}_{4}[0 \leqslant x \leqslant 0 \cdot 2$ and $x=1]$. These are shown in figure 1 . The spectrum has been analysed in terms of four bands, each having a Lorentzian shape.

\section{Analysis and discussion}

Our observations show that the spectrum in all the cases consists of four bands, two of which have strong absorption. The remaining two have weaker absorption, and in some 

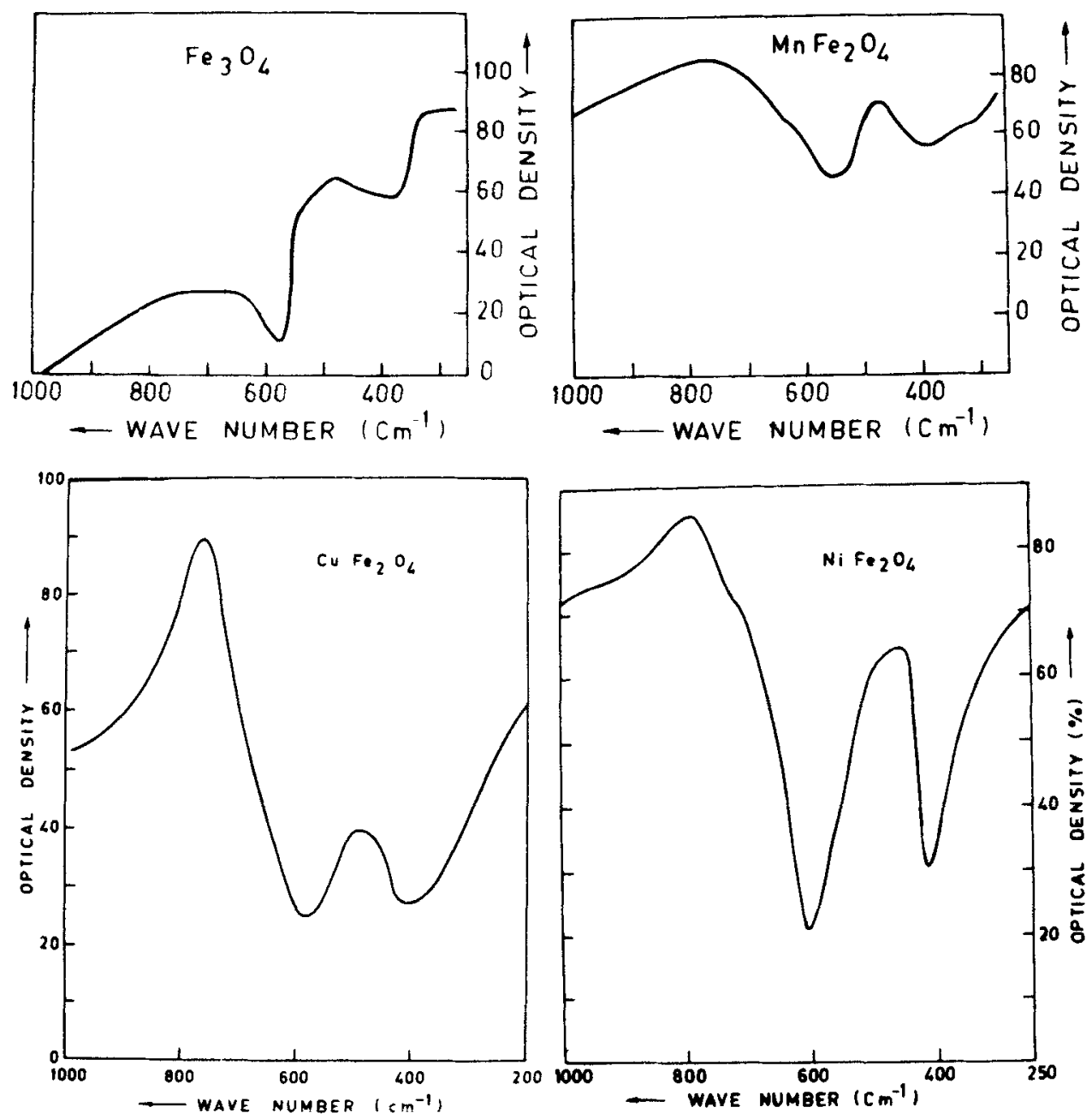

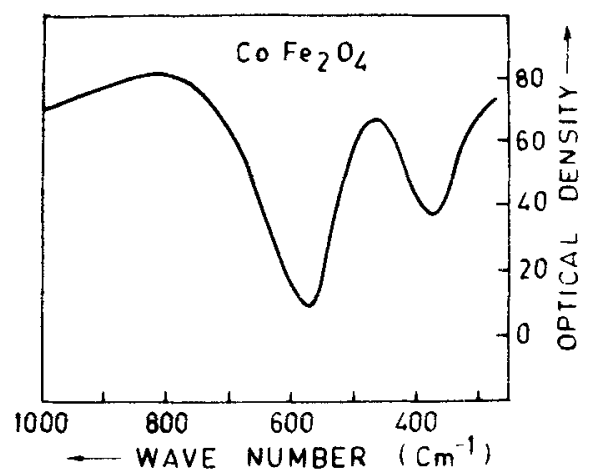

Figure 1. IR absorption of the ferrites.

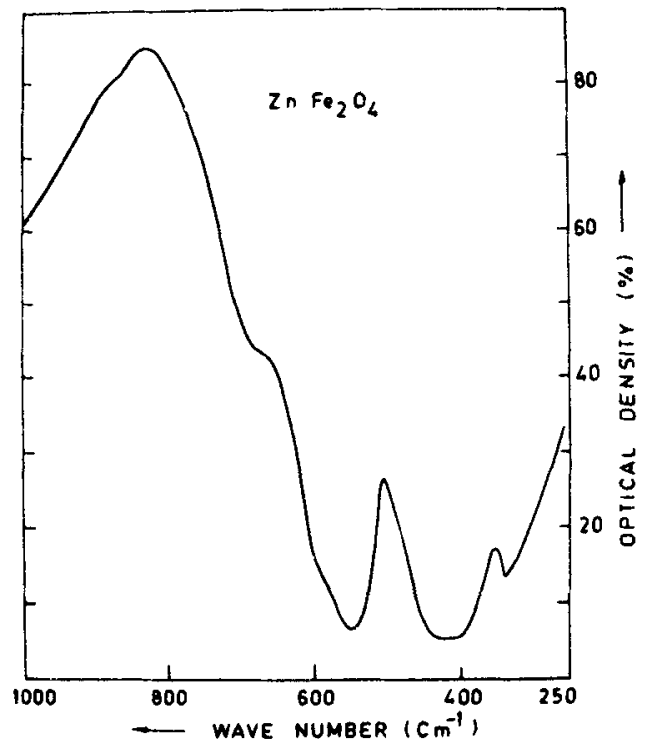


cases appear as a shoulder to the main bands. We have attributed these to the absorption by lattice vibrations having $E$ and $T_{2}$ symmetries. These type of phonon modes have been assumed by Bates and Steggles (1975) for the analysis of EPR data in $\mathrm{Fe}^{2+}$ in $\mathrm{Al}_{2} \mathrm{O}_{3}$. As there are two types of metals in the sites, we have $E^{o}, E^{t}, T_{2}^{o}$ and $T_{2}^{t}$ phonon modes where the superscripts ' $o$ ' and ' $t$ ' indicate the $E$ and $T_{2}$ symmetry of the atomic displacements around the octrahedral and tetrahedral metal ions. The bands were identified on the systematics of the observed central frequencies as the metal ion $\mathbf{M}$ was changed from $d^{5}$ to $d^{10}$ configurations. The frequency increases in the following order

$$
v\left(T_{2}^{o}\right)<v\left(T_{2}^{t}\right)<v\left(E^{o}\right)<v\left(E^{t}\right)
$$

It is difficult to assign the precise nature of atomic displacements for these modes of vibrations. We assume that those of the $T_{2}$ type would be bond-bending while the $E$ type would be bond-stretching so that in general $v\left(T_{2}\right)<v(E)$. Again we would assume that the bond stretching for tetrahedral site would lead to a higher force constant than that for the octrahedral site. On this basis we would be able to assign the bands in the order given in tables 1 and 2. The IR frequencies as a function of the number of $d$ electrons in $\mathrm{M}^{2+}$ ion are plotted in figure 2 . It is seen that with an assignment the stretching mode of the tetrahedral $t-o$ bond $\left(E^{t}\right)$ has a larger value for $\mathrm{ZnFe}_{2} \mathrm{O}_{4}$ as compared to others. This mode however has a relatively weak absorption. The stretching modes $\left(E^{\circ}\right)$ for the normal $\mathrm{Mn}$ and $\mathrm{Zn}$ ferrites have identical frequencies as these have only $\mathrm{Fe}^{3+}$ ions on the B-site. The bond stretching modes $\left(E^{\circ}\right)$ on the B-site have a strong absorption. For $\mathrm{Ni}^{2+}$, it shows a higher frequency and a narrow band. This seems to be related to the ground singlet state of the ion. Even $T_{2}^{t}$ bands in this ferrite $\left(\Delta v \approx 40 \mathrm{~cm}^{-1}\right)$ is narrower as compared to others. The bond-bending frequencies $T_{2}^{t}$ and $T_{2}^{o}$ are nearly the same as expected. In table 2 the variation of centre frequencies as one goes from normal ferrite $\left(\mathrm{ZnFe}_{2} \mathrm{O}_{4}\right)$ to inverse ferrite $\left(\mathrm{NiFe}_{2} \mathrm{O}_{4}\right)$ is given for all the four bands.

In an inverse ferrite the octahedral site is occupied by $\mathrm{Fe}^{3+}$ and the divalent ion $\mathrm{M}^{2+}$. Due to charge imbalance the oxygen ion is likely to shift towards the $\mathrm{Fe}^{3+}$ ion making

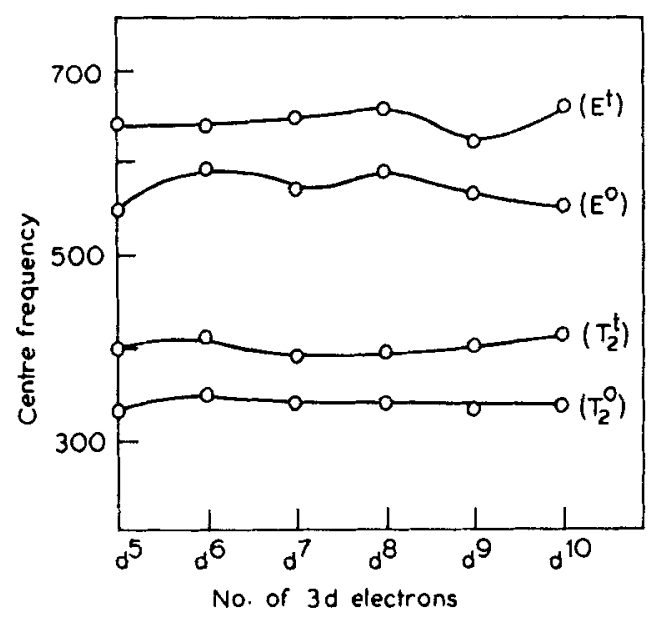

Figure 2. IR frequencies as a function of the number of $d$ electrons in $\mathrm{M}^{2+}\left(\mathrm{MFe}_{2} \mathrm{O}_{4}\right)$. 
the force constant between $\mathrm{Fe}^{3+}$ and $\mathrm{O}^{2-}$ more. Hence we expect an increase in the bond stretching $E^{o}$ phonon mode, frequencies as we go from normal to inverse spinels. This is supported by our results on $\mathrm{Zn}_{1-x} \mathrm{Ni}_{x} \mathrm{Fe}_{2} \mathrm{O}_{4}$ in which we find that $v\left(E^{o}\right)$ increase as $x$ is increased and the others $T_{2}^{o}, T_{2}^{t}$ and $E^{t}$ do not change with the type of spinel structure, given in table 2.

\section{Conclusions}

IR spectrum of spinel ferrites in the range of $200-1000 \mathrm{~cm}^{-1}$ consists four bands. These bands have been assigned on the basis of $E$ and $T_{2}$ phonon symmetries around the crystallographic metal ion sites, $A$ and $B$. On gradual change from normal to inverse spinel structure only one of the bands is affected as expected.

\section{References}

Bates C A and Steggles P 1975 J. Phys. C8 2283

Srivastava C M and Srinivasan T T 1982 J. Appl. Phys. 538148

Waldron R D 1955 Phys. Rev. 991727 